\title{
Effect of green tea supplementation on the microbiological, antioxidant, and sensory properties of probiotic milks
}

\author{
Dorota Najgebauer-Lejko
}

Received: 5 August 2013 / Revised: 12 February 2014 / Accepted: 13 February 2014 / Published online: 26 March 2014

C The Author(s) 2014. This article is published with open access at Springerlink.com

\begin{abstract}
Green tea and its constituents are known for a wide range of healthpromoting properties. They may exert antimicrobial action but without altering lactic acid bacteria. The aim of the present study was to estimate the effect of green tea addition on the selected properties of probiotic milks. Bioyogurts (fermented with ABT-1 coculture of Streptococcus thermophilus, Lactobacillus acidophilus LA-5, Bifidobacterium animalis subsp. lactis BB-12) and acidophilus milks (fermented with pure L. acidophilus LA-5 culture) with addition of 0, 5, 10 , or $15 \%(v / v)$ green tea infusion (GTI) were produced and analyzed for the antioxidant capacity by the "diphenyl picrylhydrazyl" (DPPH) and "ferric-reducing antioxidant power" (FRAP) methods, acidity, the count of starter bacteria, and sensory properties at the $1 \mathrm{st}, 7 \mathrm{th}, 14 \mathrm{th}$, and $21 \mathrm{st}$ day of cold storage. The $15 \%$ addition of GTI to the acidophilus milk significantly reduced the lactic acid production during the whole study. The GTI had no impact on the level of $S$. thermophilus and B. lactis BB-12 in bioyogurts, and its effect on the count of L. acidophilus LA-5 depended on the concentration and probiotic milk type. GTI similarly and in a dose-dependent manner enhanced the antioxidant capacity of both milk types. There were no significant differences between the sensory notes received for bioyogurts, whereas acidophilus milks with tea were less appreciated by the panelists. In conclusion, green tea could be successfully used as a functional additive for selected probiotic milks enhancing their health benefits, but the proper selection of tea additive and starter culture is recommended.
\end{abstract}

Keywords Green tea $\cdot$ Probiotics $\cdot$ Fermented milk $\cdot$ Antioxidant activity $\cdot$ Sensory evaluation

D. Najgebauer-Lejko ( $\square)$

Faculty of Food Technology, Department of Animal Product Technology,

University of Agriculture in Krakow, ul. Balicka 122, 30-149 Krakow, Poland

e-mail: d.najgebauer-lejko@ur.krakow.pl 


\section{Introduction}

Probiotics are defined as "live microorganisms which, when administered in adequate amounts, confer a health benefit on the host" (FAO/WHO 2006). Fermented dairy products, such as yogurt, are very popular food delivery systems of live probiotic cells. In recent years, due to various therapeutic benefits documented and increased consumer health awareness, the popularity of the functional dairy products containing probiotics has significantly increased. The health benefits linked with the consumption of probiotic microorganisms most commonly used in dairy products, i.e., belonging to Lactobacillus and Bifidobacterium genera, comprise prevention and relieving effects in various types of diarrhea (infantile, traveler's, antibiotic-associated), alleviation of gastrointestinal complaints, reduction of lactose intolerance, lowering serum cholesterol level, anticarcinogenic activity, prevention of urogenital infections, reduction of allergic symptoms, stimulation of the immune system, etc. (FAO/WHO 2006; Sanders et al. 2013). It is important that probiotic food products must contain living probiotic strains in an adequate matrix and in sufficient concentration at the time of consumption to reach after ingestion the postulated effect. However, the main problems connected with incorporating probiotic bacteria into fermented milk formulae are their slow growth in milk and loss of viability during storage (ElDieb et al. 2012). Different strategies can be applied to support the growth of probiotic bacteria in milk, e.g., microencapsulation of probiotic cells, heat shock of the yogurt before addition of probiotics, proper selection of starter cultures, addition of prebiotic substances (e.g., inulin, oligosaccharides), etc. (El-Dieb et al. 2012; Oliveira et al. 2012). Dave and Shah (1997) used ascorbic acid additive as oxygen scavenger to make the environment more conducive, i.e., with reduced oxygen content and redox potential, for these microaerophilic (Lactobacillus acidophilus) or strictly anaerobic (Bifidobacterium ssp.) microorganisms. Probiotic milks are also often supplemented with other active components with the aim to provide additional functional properties, like plant sterols and stanol esters as well as antioxidative substances (Saxelin 2008).

Tea is the second, next to water, most commonly consumed beverage worldwide. Many studies have been conducted which demonstrated beneficial effects of tea and its constituents on human health. The health claims include reduction of risk of cancer, arteriosclerosis and cardiovascular diseases, neural and obesity problems, diabetes, pulmonary ailments, and diseases of the kidneys and liver, and antibacterial and antiviral effects. The most important bioactive substances responsible for these health-giving properties present in tea are flavonoids (namely, catechins and their derivatives) (Jain et al. 2006). Among all functions of polyphenols, their antioxidant activity is the most frequently studied. Their in vitro action as antioxidants refers to the scavenging activity against reactive oxygen and nitrogen species and the ability to sequester metal ions (Bancirova 2010; Zhu et al. 2006). Polyphenols have been also reported as very potent antimicrobial agents (von Staszewski et al. 2011). The study of Almajano et al. (2008) indicated that tea compounds characterized by the highest antioxidant power are simultaneously the most effective as microbiological inhibitors. Phenolics present in tea and wine are able to modify the intestinal microbiota by inhibiting the growth of pathogenic 
bacteria and increasing the level of commensal bacteria, including bifidobacteria, which suggests their prebiotic effect (Hara 1997; Lee et al. 2006; Queipo-Ortuño et al. 2012). Catechins from tea and other phenolic compounds have also been shown to inhibit the growth of many food-borne bacteria and fungi in milk with little effect on lactic acid bacteria (Almajano et al. 2008; O'Connell and Fox 2001). The sensitivity of lactic acid bacteria (LAB) and bifidobacteria to the phenolic compounds depends on the bacterial species and strain, as well as chemical structure and concentration of the polyphenols (Tabasco et al. 2011). Some of the resistant strains, e.g., Lactobacillus plantarum, Lactobacillus casei Shirota, are also able to metabolize these compounds (Lee et al. 2006; Rodríguez et al. 2009).

In addition to their benefits for human health, phenolics also affect sensory properties, i.e., flavor, taste (astringency), and color of the food products (Rodríguez et al. 2009). These facts make tea not only very popular as a beverage, but its extracts are also successfully incorporated into food systems, e.g., ice cream mixes, yogurt, and fruit-flavored milk drinks (O’Connell and Fox 2001).

Previous studies demonstrated that addition of tea extracts to the conventional yogurt, i.e., containing Streptococcus thermophilus and Lactobacillus delbrueckii subsp. bulgaricus, did not affect the viability of starter microorganisms (Jaziri et al. 2009) or the stimulating effect was observed (Najgebauer-Lejko et al. 2011). However, there is lack of information on the effect of tea in fermented milks containing probiotic bacteria. This study was established to estimate the effect of green tea infusion (GTI) supplementation in different concentrations $(0,5,10$, or $15 \% v / v)$ on the antioxidant capacity measured as scavenging activity against DPPH radical and ferric-reducing ability (FRAP) of bioyogurts (milks fermented with the ABT-1 coculture of S. thermophilus and two probiotic strains, i.e., L. acidophilus LA-5 and Bifidobacterium animalis ssp. lactis BB-12) and acidophilus milks (fermented with pure L. acidophilus LA-5 culture) and to determine whether GTI can affect viability of starter cultures, including probiotic bacteria, during a 3-week cold storage. Moreover, the acidity and sensory quality of the plain and supplemented probiotic milks were evaluated.

\section{Materials and methods}

\subsection{Materials}

Fresh, raw, cows' milk ( 20 L) for the production of probiotic milks was obtained from a local milk farm in Dziekanowice (Poland). Chinese leaf green tea (Yunnan Tea Garden Group Shareholding Co., Ltd., Kunming, China) was purchased from the local supermarket. Instant nonfat milk powder was purchased from Dairy Company in Gostyn (Poland). ABT-1 DVS coculture, consisting of $S$. thermophilus, L. acidophilus (LA-5), and B. lactis (BB-12), and L. acidophilus LA-5 monoculture were obtained from Chr. Hansen (Hoersholm, Denmark).

Folin-Ciocalteu's phenol reagent, Trolox, and gallic acid monohydrate were purchased from Fluka (Buchs, Switzerland; Copenhagen, Denmark; and Madrid, Spain), and 2,2-diphenyl-1-picrylhydrazyl (DPPH) and 2,4,6-tris(2-pyridyl)-s-triazine (TPTZ) 
from Sigma-Aldrich (Steinheim, Germany and Buchs, Switzerland). All other chemicals used were of analytical reagent grade.

\subsection{Preparation of tea infusion}

Green tea leaves $(40 \mathrm{~g})$ were infused in $800 \mathrm{~mL}$ of freshly boiled water in a glasscovered beaker for $15 \mathrm{~min}$. The leaves were then removed and the infusion cooled to ambient temperature. To achieve the same content of milk solids in all final products, a boiled-and-cooled-to-ambient-temperature water in the proper amounts was added to milk destined for the nonsupplemented (natural) probiotic milks (bioyogurt and acidophilus milk) as well as for the milks with 5 or $10 \%(v / v)$ of tea infusions.

\subsection{Manufacturing of bioyogurts and acidophilus milks}

The preparation of milk for probiotic milk products comprised centrifugation $(3,500 \times g$, $45^{\circ} \mathrm{C}$ ) to reach $2 \%$ fat level, standardization with nonfat milk powder (NMP) to achieve $15 \%$ dry matter content in the final products, homogenization $\left(60{ }^{\circ} \mathrm{C}\right.$, $6 \mathrm{MPa}$ ), pasteurization $\left(85^{\circ} \mathrm{C}, 15 \mathrm{~min}\right)$, and cooling to $38^{\circ} \mathrm{C}$. Subsequently, the bulk milk was inoculated with the ABT-1 starter $(0.08 \mathrm{~g}$ per $1 \mathrm{~L}$ of milk) for bioyogurts or LA-5 culture ( $0.1 \mathrm{~g}$ per $1 \mathrm{~L}$ of milk) for acidophilus milks. Each treatment was divided into four equal portions; mixed with proper amounts of GTI or/and water to reach 0, 5, 10 , or $15 \%$ of GTI; and poured into 200 -mL sterile glass jars. The incubation proceeded at $37^{\circ} \mathrm{C}$ for $10-12 \mathrm{~h}$ (the same time for all milks) until firm coagula were formed $(\mathrm{pH}$ of 4.6-4.8 for all treatments except for acidophilus milk with $15 \%$ of GTI which was higher). Subsequently, fermented milk products were immediately cooled and stored at $4{ }^{\circ} \mathrm{C}$ prior to analyses. The samples were subjected to analyses directly after production and after 7,14 , and 21 days of refrigerated storage at $\sim 4{ }^{\circ} \mathrm{C}$.

\subsection{Analyses of tea infusion}

Green tea infusion was analyzed for the total level of polyphenolic compounds using the Folin-Ciocalteu method by the procedure described by Rusak et al. (2008). Results expressed as milligrams of gallic acid equivalents (GAE) per liter of infusion were recalculated per $100 \mathrm{~g}$ of the respective milk. Additionally, the content of flavan-3-ols, i.e., (-)-epicatechin (EC), (-)-epigallocatechin (EGC), (-)-epigallocatechin gallate (EGCG), and (-)-epicatechin gallate (ECG), was determined by means of highperformance liquid chromatography (HPLC). The catechins were identified using L-7000 LaChrom liquid chromatograph with UV/Vis detector (Merck-Hitachi, Tokyo, Japan) equipped with a reversed phase (ODS) column (Thermo Scientific, USA; $25 \mathrm{~mm} \times 0.4 \mathrm{~cm} \times 5 \mu \mathrm{m})$. The sample preparation and exact analysis followed the procedure described by Socha et al. (2013). The determination of ferric-reducing antioxidant power (FRAP) and scavenging rate of 2,2-diphenyl-1-picrylhydrazyl (DPPH) radical followed the procedures described in the previous work of Najgebauer-Lejko et al. (2011). The FRAP was expressed as millimoles $\mathrm{Fe}^{2+}$ equivalents (E) per liter, and the DPPH antiradical activity as antiradical power (ARP) calculated relative to the ARP of Trolox in millimoles of Trolox equivalents (TE) per kilogram sample. 


\subsection{Analyses of fermented milks}

In all samples, $\mathrm{pH}$ was measured using an Elmetron (Zabrze, Poland) $\mathrm{CP}-411 \mathrm{pH}$ meter. Titratable acidity expressed as percentage of lactic acid was determined according to the Soxhlet-Henkel method (Polish Standard, PN-A-86061:2002).

The level of $S$. thermophilus in bioyogurts was assessed using M17 agar (Biocorp, Warszawa, Poland) under aerobic conditions. For enumeration of L. acidophilus, MRS-maltose agar was prepared from the same ingredients and procedure as MRS agar (ISO 7889:2003) but by replacing glucose with an equal amount of maltose and adjusting $\mathrm{pH}$ to 6.4. The Petri dishes for lactobacilli enumeration in bioyogurts and acidophilus milks were incubated respectively under aerobic conditions or in 2.5-L anaerobic jars using Anaerocult ${ }^{\circledR} \mathrm{C}$ sachets (Merck, Darmstadt, Germany). The count of bifidobacteria was evaluated using nalidixic acid, neomycin sulfate, lithium chloride, and paromomycin sulfate (NNLP)-MRS agar (MRS supplied by Biocorp, Warszawa, Poland) in anaerobic incubators of our own construction filled with $\mathrm{CO}_{2}$. All cultures were incubated at $37{ }^{\circ} \mathrm{C}$ for 2 (streptococci) or 3 (lactobacilli, bifidobacteria) days.

The evaluation of the antioxidant capacity was also performed using DPPH and FRAP methods by the same procedures as for the tea infusion. The sensory evaluation was performed according to the PN-ISO 6658 standard (1998) using a 5-point scale (from 5-excellent to 1 - very bad) by a trained panel of five judges. The fermented milk samples were presented to panelists in identical plastic cups labeled with random numbers and in random order. The following properties were assessed: color, taste, odor, consistency, and general appearance. The overall preference was calculated taking into account the proper indexes of importance for each quality attribute $(0.10,0.35$, $0.15,0.25,0.15$, respectively).

\subsection{Statistical analysis}

All experiments were performed in three series and in duplicate and results expressed as mean \pm standard error. Estimation of the effect of tea addition and time of storage was conducted using ANOVA, and where the significant effect was found, the significance of differences between the means was determined on the basis of Duncan's test at the significance level of $P \leq 0.05$. The statistical analysis was performed using Statistica 8.0 software (StatSoft Inc., Tulsa, OK, USA).

\section{Results}

\subsection{Composition and acidity of fermented milks}

The bioyogurts and acidophilus milks produced in this study contained on average $15.2 \%$ of dry matter $(\mathrm{dm}), 1.7 \%$ of fat, and $4.8 \%$ of protein as well as $0,0.07,0.15$, or $0.22 \mathrm{~g}$ of tea dry matter per $100 \mathrm{~g}$ of fermented milk, respectively, for each level of supplementation (data not shown). The addition of GTI to the examined probiotic milks resulted in the enrichment of their composition with tea polyphenols in the amount of $57.9,115.8$, and $173.8 \mathrm{mg}$ GAE per $100 \mathrm{~g}$ of fermented milk (for 5, 10, or $15 \%$ of tea 
supplementation, respectively), as determined by the Folin-Ciocalteu method. HPLC analysis revealed that the green tea infusion used for milk supplementation contained $81.25 \pm 0.23$ (-)-epicatechin (EC), $148.47 \pm 0.24$ (-)-epicatechin gallate (ECG), 147.36 \pm 4.78 (-)-epigallocatechin (EGC), and 242.86 \pm 1.90 (-)-epigallocatechin gallate (EGCG) $\left(\mathrm{mg} \cdot 100 \mathrm{~mL}^{-1}\right.$ of tea infusion).

Directly after production, it could be observed that the $\mathrm{pH}$ of the bioyogurts and acidophilus milks was slightly higher for higher levels of green tea supplementation, which was accompanied by the lower values of titratable acidity (Table 1). This phenomenon was much more pronounced in the case of milk products fermented solely with L. acidophilus LA-5 showing the noticeable difference of 0.51 units and $0.42 \%$ lactic acid, respectively, for initial $\mathrm{pH}$ and titratable acidity noted between plain acidophilus milk (NA) and that with $15 \%$ of green tea infusion (GTA-15\%). The significant difference in acidity of NA and GTA-15\% was also observed after storage. Generally, the $\mathrm{pH}$ values decreased and the level of lactic acid slightly increased throughout the storage, although observed $\mathrm{pH}$ reduction was statistically significant $(P \leq 0.05)$ only for acidophilus milk with $15 \%$ of green tea. The drop in $\mathrm{pH}$ value observed for this treatment was above twice that evaluated for the other milks fermented with L. acidophilus LA-5 monoculture.

Table 1 Changes of the $\mathrm{pH}$, titratable acidity, and sensory notes of bioyogurts and acidophilus milks during cold storage $(n=6)$

\begin{tabular}{clllllllll}
\hline Sample & NY & GTY-5\% & GTY-10\% & GTY-15\% & NA & GTA-5\% & GTA-10\% & GTA-15\% & SE \\
\hline Day & $\mathrm{pH}$ & & & & & & & & \\
1 & $4.54 \mathrm{a}$ & $4.61 \mathrm{a}$ & $4.70 \mathrm{ab}$ & $4.78 \mathrm{ab}$ & $4.51 \mathrm{a}$ & $4.62 \mathrm{a}$ & $4.69 \mathrm{ab}$ & $5.02 \mathrm{bA}$ & 0.05 \\
7 & $4.54 \mathrm{ab}$ & $4.52 \mathrm{ab}$ & $4.58 \mathrm{ab}$ & $4.70 \mathrm{ab}$ & $4.38 \mathrm{a}$ & $4.48 \mathrm{ab}$ & $4.59 \mathrm{ab}$ & $4.83 \mathrm{~b}$ & 0.05 \\
14 & $4.50 \mathrm{ab}$ & $4.48 \mathrm{ab}$ & $4.60 \mathrm{ab}$ & $4.64 \mathrm{ab}$ & $4.32 \mathrm{a}$ & $4.48 \mathrm{ab}$ & $4.60 \mathrm{ab}$ & $4.74 \mathrm{~b}$ & 0.04 \\
21 & $4.48 \mathrm{a}$ & $4.50 \mathrm{a}$ & $4.50 \mathrm{a}$ & $4.65 \mathrm{a}$ & $4.34 \mathrm{a}$ & $4.45 \mathrm{a}$ & $4.59 \mathrm{a}$ & $4.64 \mathrm{aB}$ & 0.03 \\
Day & Titratable acidity (\% lactic acid) & & & & & & \\
1 & $1.07 \mathrm{ab}$ & $0.91 \mathrm{ab}$ & $0.87 \mathrm{ab}$ & $0.70 \mathrm{a}$ & $1.16 \mathrm{~b}$ & $1.07 \mathrm{ab}$ & $0.95 \mathrm{ab}$ & $0.74 \mathrm{a}$ & 0.05 \\
7 & $1.13 \mathrm{ab}$ & $1.12 \mathrm{ab}$ & $1.08 \mathrm{ab}$ & $0.75 \mathrm{a}$ & $1.25 \mathrm{~b}$ & $1.22 \mathrm{~b}$ & $1.09 \mathrm{ab}$ & $0.94 \mathrm{ab}$ & 0.05 \\
14 & $1.12 \mathrm{ab}$ & $1.14 \mathrm{ab}$ & $0.96 \mathrm{ab}$ & $0.81 \mathrm{a}$ & $1.31 \mathrm{~b}$ & $1.08 \mathrm{ab}$ & $1.00 \mathrm{ab}$ & $0.92 \mathrm{ab}$ & 0.05 \\
21 & $1.13 \mathrm{ac}$ & $1.08 \mathrm{ac}$ & $0.94 \mathrm{ac}$ & $0.81 \mathrm{a}$ & $1.31 \mathrm{c}$ & $1.24 \mathrm{bc}$ & $1.11 \mathrm{ac}$ & $0.90 \mathrm{ab}$ & 0.04 \\
Day & Sensory evaluation (scores) & & & & & & \\
1 & $4.77 \mathrm{a}$ & $4.72 \mathrm{a}$ & $4.78 \mathrm{a}$ & $4.70 \mathrm{a}$ & $4.53 \mathrm{a}$ & $4.19 \mathrm{a}$ & $4.20 \mathrm{a}$ & $4.17 \mathrm{a}$ & 0.07 \\
7 & $4.78 \mathrm{c}$ & $4.69 \mathrm{bc}$ & $4.79 \mathrm{c}$ & $4.62 \mathrm{bc}$ & $4.04 \mathrm{ab}$ & $3.81 \mathrm{a}$ & $3.71 \mathrm{a}$ & $3.52 \mathrm{a}$ & 0.12 \\
14 & $4.86 \mathrm{~d}$ & $4.82 \mathrm{~d}$ & $4.79 \mathrm{~d}$ & $4.71 \mathrm{~cd}$ & $4.43 \mathrm{bcd}$ & $4.07 \mathrm{ac}$ & $3.83 \mathrm{ab}$ & $3.67 \mathrm{a}$ & 0.10 \\
21 & $4.66 \mathrm{~b}$ & $4.60 \mathrm{~b}$ & $4.48 \mathrm{~b}$ & $4.43 \mathrm{~b}$ & $4.20 \mathrm{ab}$ & $3.99 \mathrm{ab}$ & $3.68 \mathrm{a}$ & $4.14 \mathrm{ab}$ & 0.10 \\
\hline
\end{tabular}

Means within each row not sharing the same lowercase letter are statistically different $(P \leq 0.05)$; different capital letters given in columns denote the statistical difference $(P \leq 0.05)$ between means for a given feature $N Y$ natural (plain) bioyogurt; GTY-5\%, GTY-10\%, and GTY-15\%-bioyogurts with 5, 10, and 15\% $(v / v)$ of green tea infusion, respectively; $N A$ natural (plain) acidophilus milk; GTA-5\%, GTA-10\%, and GTA-15\%acidophilus milks with 5, 10, and $15 \%$ of green tea infusion, respectively; $S E$ standard error of the mean 


\subsection{Antioxidant capacity of probiotic milks as affected by green tea supplementation}

Two methods were employed for measuring antioxidant activity of fermented milks, i.e., DPPH assay, which measures the scavenging activity of the DPPH radical by antioxidant substances present in the examined sample, and FRAP, which allows to estimate the ability to reduce prooxidant metal ions. The results of FRAP evaluation expressed as millimoles $\mathrm{Fe}^{2+}$ E per liter and DPPH analysis given as ARP in millimoles of Trolox equivalents (TE) per kilogram sample are presented in Figs. 1 and 2, respectively.

In the present study, ARP values evaluated for the plain bioyogurt (NY) and acidophilus milk (NA) fluctuated in the range of $0.21-0.28 \mathrm{mmol} \mathrm{TE} \mathrm{kg}^{-1}$ with no significant differences between these two types of fermented milks $(P>0.05)$. The FRAP values were slightly higher for NA $\left(1.25-1.61 \mathrm{mmol} \mathrm{Fe}^{2+} \mathrm{E} \mathrm{L}^{-1}\right)$ than those for NY $\left(0.89-1.05 \mathrm{mmol} \mathrm{Fe}^{2+} \mathrm{E} \mathrm{L}^{-1}\right)$, but also in this case, the differences were insignificant. Green tea infusion was characterized by noticeably higher antioxidant capacity with $41.60 \pm 0.73 \mathrm{mmol} \mathrm{TE} \mathrm{kg}{ }^{-1}$ and $72.76 \pm 6.74 \mathrm{mmol} \mathrm{Fe}^{2+} \mathrm{E} \mathrm{L}^{-1}$ average ARP and FRAP values, respectively (data not shown).

The strong antioxidative properties of green tea resulted in significantly higher ARP (9-29-fold) and FRAP (3-13-fold) values of all supplemented fermented milks when
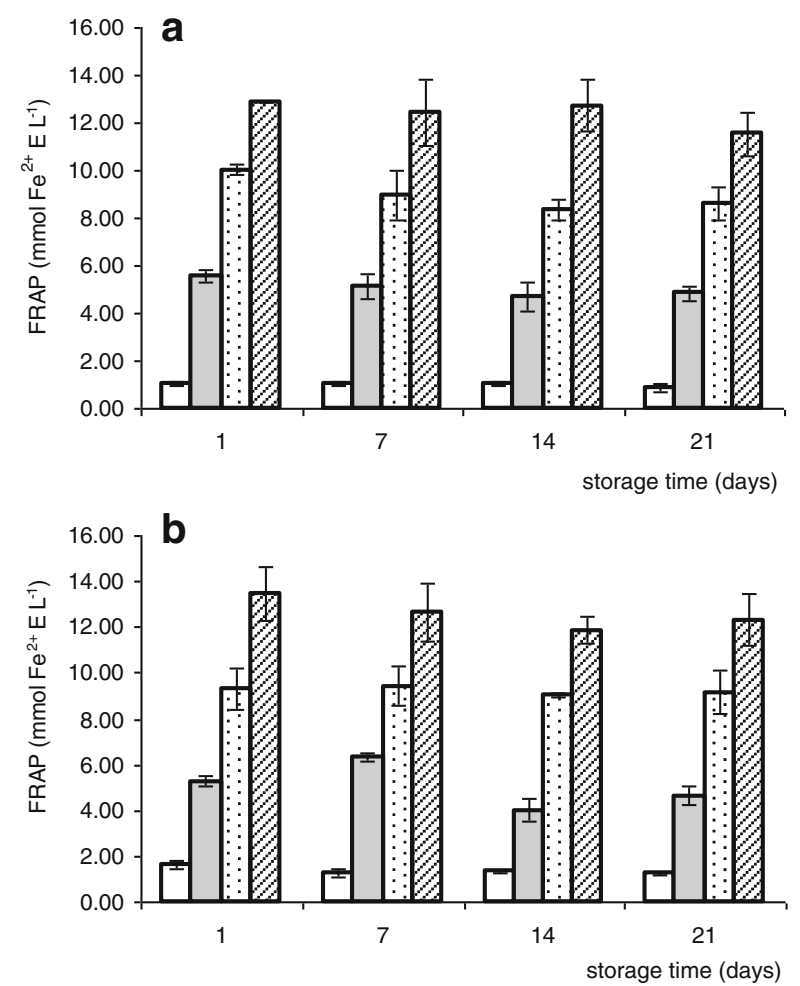

Fig. 1 Changes of the ferric-reducing antioxidant power (FRAP) values of bioyogurts (a) and acidophilus milks (b) during refrigerated storage ( $\square$ natural bioyogurt/acidophilus milk; $\square$ bioyogurt/acidophilus milk with $5 \%$ of green tea infusion; $: \because$ bioyogurt/acidophilus milk with $10 \%$ of green tea infusion; $\square$ bioyogurt/ acidophilus milk with $15 \%$ of green tea infusion; means \pm SE, $n=6$ ) 

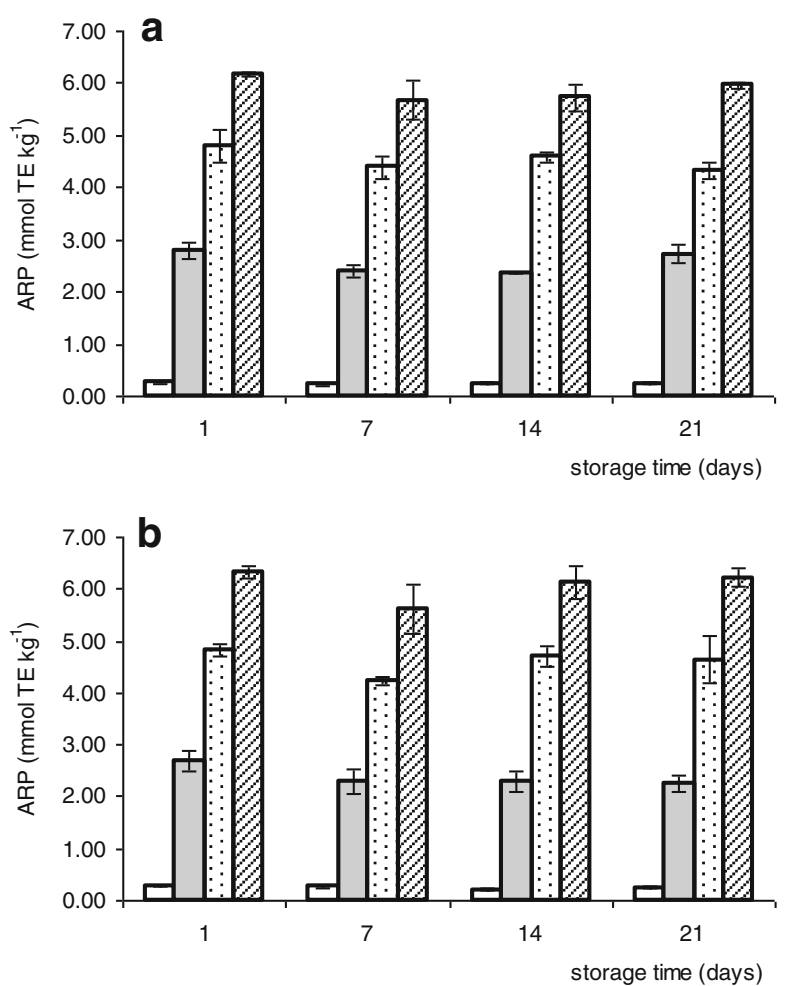

Fig. 2 Changes of the antiradical power (ARP) values of bioyogurts (a) and acidophilus milks (b) during refrigerated storage ( $\square$ natural bioyogurt/acidophilus milk; $\square$ bioyogurt/acidophilus milk with $5 \%$ of green tea infusion; $::$ bioyogurt/acidophilus milk with $10 \%$ of green tea infusion; $\mathbb{Z}$ bioyogurt/acidophilus milk with $15 \%$ of green tea infusion; means \pm SE, $n=6$ )

compared with the natural treatments. The higher level of tea additive was applied, the higher radical-scavenging ability and ferric-reducing activity was observed, with statistically significant differences between the respective results $(P \leq 0.05)$. There were no differences between bioyogurts and acidophilus milks with the same level of supplementation. For all products, the FRAP and ARP values determined after 3 weeks of storage were lower than the initial by $2-22 \%$ and $2-16 \%$ (respectively), but the rate of this decrease was statistically insignificant.

\subsection{Effect of green tea addition on the viability of the starter bacteria}

The effect of green tea addition to the bioyogurts and acidophilus milks on the number of starter microorganisms is shown in Fig. 3a-d. As regards probiotic strains, lactobacilli were present in the number of 7.21-8.29 $\log \mathrm{cfu} \mathrm{g}^{-1}$ (bioyogurts) or 8.72-9.02 $\log \mathrm{cfu} \mathrm{g}^{-1}$ (acidophilus milks) and the count of bifidobacteria in bioyogurts reached the level of 6.66-7.54 $\log \mathrm{cfu}^{-1}$. The levels of all starter bacteria in both types of probiotic milks and in all treatments remained practically unchanged after 3 weeks of refrigerated storage (no significant differences at $P \leq 0.05$ ).

$S$. thermophilus with the number of 8.47-9.12 $\log \mathrm{cfu}^{-1}$ was the prevailing species in bioyogurts constituting from 69 to $95 \%$ (depending on storage duration and level of 

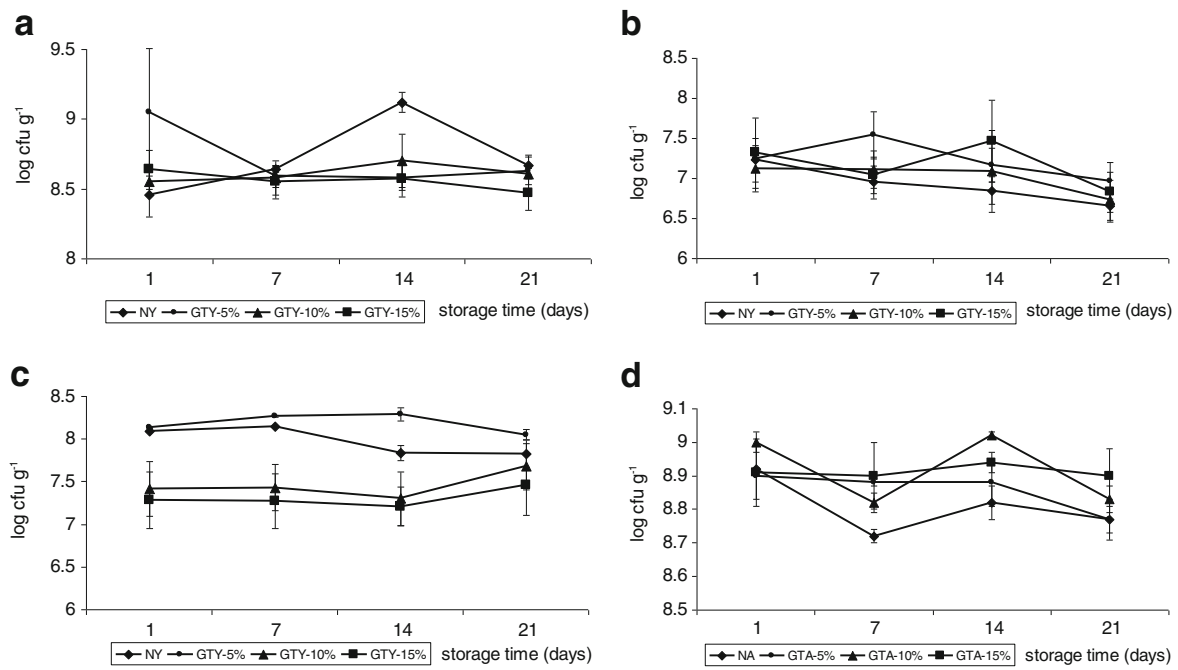

Fig. 3 Viability of starter bacteria in probiotic milks with or without green tea additive during refrigerated storage: a Streptococcus thermophilus count in bioyogurts, b Bifidobacterium animalis ssp. lactis count in bioyogurts, c Lactobacillus acidophilus count in bioyogurts, and d Lactobacillus acidophilus count in acidophilus milks. NY natural bioyogurt; GTY-5\%, GTY-10\%, and GTY-15\%-bioyogurt with 5, 10, and $15 \%$ of green tea infusion, respectively; $N A$ natural acidophilus milk; GTA-5\%, GTA-10\%, and GTA-15\%-acidophilus milk with 5, 10, and 15\% of green tea infusion, respectively (bars denote standard error of the mean)

tea supplementation) of all starter microbiota. As revealed by the analysis of variance (data not shown), the green tea additive did not affect the count of streptococci in bioyogurts. Some fluctuations observed in their number in the plain bioyogurt (NY) and the one containing 5\% of green tea infusion (GTY-5\%; Fig. 3a) during storage were insignificant. In bioyogurts with higher levels of tea incorporation, the concentration of cocci was stable within the studied period.

Statistical analysis revealed that the number of bifidobacteria was unaffected by the bioyogurt type, but it is worth to emphasize that the count of these probiotic bacteria remained at a higher level for a longer period of time in fermented milks enriched with green tea (decrease below $7 \log \mathrm{cfu} \mathrm{g}^{-1}$ after 3 weeks in bioyogurts with green tea vs. 1 week for NY). The concentration of $B$. animalis subsp. lactis BB-12 in overall population of starter microorganisms determined in the obtained probiotic yogurts ranged between 1 and 5\% for nonsupplemented and fortified with 5 and 10\% of GTI bioyogurts, whereas in GTY-15\%, the average bifidobacteria share was $\sim 10 \%$. According to the manufacturer's stated colony-forming unit counts, the lactobacilli to bifidobacteria to streprococci ratio at inoculation should have been $2: 2: 1$. Thus, major changes occurred in the strain ratio during fermentation.

The effect of GTI incorporation into the bioyogurt formulation on the viability of L. acidophilus LA-5 was dose-dependent. The higher the dosage of GTI, the lower number of these bacteria evaluated in fermented milk. The $5 \%$ green tea supplementation resulted in significantly higher number of lactobacilli (by almost one log cycle) than higher doses of GTI. In relation to the plain bioyogurt, the difference was negligible.

Acidophilus milks contained higher amounts of lactobacilli than bioyogurts (8.729.02 vs. 7.21-8.29 $\log \mathrm{cfu} \mathrm{g}^{-1}$ ). In the case of milk fermented with L. acidophilus LA-5 in monoculture, the green tea infusion at 10 and $15 \%$ influenced the higher level of 
bacteria than 0 or $5 \%$ treatment. The milks which contained 5 and $15 \%$ of GTI were very stable as regards lactobacilli content within the study period, whereas in NA and GTA-10\%, some fluctuations in the number of these bacteria were observed.

\subsection{Effect of tea addition on the sensory properties of probiotic milks}

The incorporation of tea extracts into the bioyogurt had no significant influence on the notes received in the sensory evaluation (Table 1). The notes fluctuated in the range of 4.43-4.86 and were slightly lower at the end of the experiment, although the storage time was an insignificant factor as regards this feature. Acidophilus milks were worse appreciated by the panelists than bioyogurts (3.52-4.53), which was connected with less acceptable flavor as well as consistency and general appearance mainly due to visible whey separation (data not shown). In this case, fermented milks supplemented with tea received lower notes than plain acidophilus milk and with one exception (GTA-15\% at the 21st day), the higher tea additive was related to lower notes.

\section{Discussion}

The main phenolic compounds present in green tea responsible for its high antioxidant potential are catechins: (-)-epigallocatechin gallate (EGCG), (-)-epigallocatechin (EGC), (-)-epicatechin gallate (ECG), and (-)-epicatechin (EC) as well as gallic acid (Cabrera et al. 2003). Research data usually focus on EGCG as the very powerful tea antioxidant. EGCG was the most abundant flavan-3-ol compound detected in green tea infusion in the present study. Milk also possesses some antioxidant activity resulting from the presence of such components as bioactive peptides derived from both caseins and whey proteins, lactoferrin, urate, ascorbate, $\alpha$-tocopherol, $\beta$-carotene, coenzyme Q10, and enzymatic systems (superoxide dismutase, catalase, and glutathione peroxidase), which is a property that in fermented milk can be further improved as starter microorganisms also possess some antioxidant potential (Chen et al. 2003; Kullisaar et al. 2002). Much more higher DPPH radical-scavenging and ferric-reducing abilities of green tea resulted in certain enhancement of this property in fermented milks with every increase of tea supplementation.

The results obtained for acidity measurement in this study, which suggest that GTI slowed down the acidity development during fermentation and storage, are opposite to those obtained for the conventional yogurt, where 5-15\% green tea additive (regardless of the concentration) resulted in significantly lower $\mathrm{pH}$ values and simultaneously higher L. delbrueckii subsp. bulgaricus count when compared with the plain yogurt (Najgebauer-Lejko et al. 2011). On the other hand, Jaziri et al. (2009) demonstrated that green tea extract had no effect on the lactic acid concentration and bacteria survival in yogurts, while data from Gaudreau et al. (2013) are at least partially in agreement with the detrimental effect of higher concentrations of tea extracts on the growth of lactobacilli in bioyogurts as observed in the present study. In ABT yogurt culture used in the present study, L. bulgaricus is excluded, which significantly reduces the $\mathrm{pH}$ decrease during production and storage as this species is a better lactic acid producer than L. acidophilus and Bifidobacterium sp. (Lourens-Hattingh and Viljoen 2001; Shihata and Shah 2002). 
To exert the beneficial health effects, the amount of probiotic bacteria in the food product should be adequately high, i.e., $10^{6}-10^{8} \mathrm{cfu} \mathrm{mL}^{-1}$ throughout the entire shelf life (Ghoddusi and Hassan 2011). The level of L. acidophilus and B. animalis ssp. lactis evaluated during the whole storage period (21 days) in this study met this criterion. Enhanced viability of bifidobacteria in tea-supplemented yogurts during the first 2 weeks of refrigerated storage may be connected with higher $\mathrm{pH}$ values of bioyogurts containing higher amounts $(10$ and $15 \%)$ of green tea $(\mathrm{pH} \geq 4.6)$ as growth of most strains of bifidobacteria is retarded at $\mathrm{pH}$ values below 4.6 (Lourens-Hattingh and Viljoen 2001).

In the study conducted on milk fermented with traditional yogurt culture, the positive effect of green tea infusion (the same tea and preparation procedure as in the present study) at the concentration of 10 and $15 \%$ was observed, whereas $5 \%$ supplementation negatively affected the population of streptococci when compared with natural yogurt (Najgebauer-Lejko et al. 2011). On the contrary, Jaziri et al. (2009) reported that green or black tea had no effect on the lactic acid bacteria in yogurt. This suggests that the effect of tea supplementation on the growth and survival of selected starter microorganisms in milk systems, among other factors (type of tea and its composition, procedure of tea yogurt preparation, etc.), depends also on the composition of starter microbiota used for fermentation.

In the present study, LA-5 probiotic strain of L. acidophilus was used for milk fermentation in the monoculture and in the coculture with $S$. thermophilus and B. lactis BB-12. The viability of lactobacilli was influenced by both the green tea concentration and type of fermented milk product. These findings are in concordance with the observations of Tabasco et al. (2011) that the sensitivity of lactic acid bacteria (LAB) and bifidobacteria to the phenolic compounds depends on the bacterial species and strain as well as chemical structure and concentration of the polyphenols. In their study, the growth of tested L. acidophilus LA- 5 strain was negatively affected by the addition of flavan-3-ol-enriched grape seed extract. On the contrary, Hervert-Hernández et al. (2009) reported the stimulatory effect of grape phenolic extract and some of its pure components (tannic acid, catechins) on the growth of probiotic lactobacilli (L. acidophilus CET 903). Almajano et al. (2008) showed the inhibitory effect of extracts of different teas against food-borne pathogens, e.g., Bacillus cereus, Micrococcus luteus, and Pseudomonas aeruginosa, whereas L. acidophilus exhibited exceptional resistance to all extracts studied. The different response of $L$. acidophilus in its pure culture and coculture to the different concentrations of green tea extract applied needs to be considered taking into account the interactions between starter microorganisms in ABT yogurt. The effect of the accompanying species used to ferment milk on the survival of L. acidophilus and Bifidobacterium spp. was reported by LourensHattingh and Viljoen (2001). Moreover, as some species of the lactobacilli were demonstrated to have the ability to metabolize phenolic compounds (Lee et al. 2006; Rodríguez et al. 2009), the effect of the potential phenolic metabolites cannot be excluded.

Saxelin and coauthors (2003) stated that despite the health benefits, fermentation of milk with pure probiotic strain may result in a product with texture and taste that does not meet the consumer approval; therefore, the common practice is to use probiotic strains together with standard starter cultures, e.g., yogurt. This often takes place in the case of acidophilus milk as L. acidophilus is a homofermentative bacterium that gives 
plain acid flavor, which is frequently perceived as too sour with lack of real aromatic flavor (Lengkey and Adriani 2009). The results of our study suggest that the main taste sensations found in green tea, such as astringency and bitterness (Chaturvedula and Prakash 2011), did not compose well with the taste of acidophilus milk. The possible phenolic metabolites (not studied herein) may also influence sensory characteristic of the product.

\section{Conclusion}

The incorporation of GTI in a dose-dependent manner increased antiradical and ferricreducing power of probiotic milks with no significant differences between the bioyogurts and acidophilus milks with the same level of supplementation. Bioyogurts with different levels of green tea infusion did not vary as regards the average counts of $S$. thermophilus and B. animalis ssp. lactis BB-12, but GTI at all applied concentrations maintained the viability of bifidobacteria at the level above $7 \log \mathrm{cfu}^{-1}$ for an additional 2 weeks compared to the plain bioyogurt. Green tea at the concentration of $5 \%$ was more beneficial for the viability of L. acidophilus in bioyogurt, whereas 10 and $15 \%$ positively affected LA-5 growth in monoculture.

In summary, the results of the present study suggest that green tea can be successfully employed as a functional supplement for probiotic milks, adding extra value to the known health benefits of probiotics, but the proper amount of tea additive and cultures for milk fermentation need to be carefully chosen.

Acknowledgments The author would like to thank Robert Socha for HPLC study. The present research was supported by the funding of Polish Ministry of Science and Higher Education (DS/3700/WTŻ/13).

Open Access This article is distributed under the terms of the Creative Commons Attribution License which permits any use, distribution, and reproduction in any medium, provided the original author(s) and the source are credited.

\section{References}

Almajano MP, Carbó R, Jiménez JAL, Gordon MH (2008) Antioxidant and antimicrobial activities of tea infusions. Food Chem 108:55-63

Bancirova M (2010) Comparison of the antioxidant capacity and the microbial activity of black and green tea. Food Res Int 43:1379-1382

Cabrera C, Giménez R, López MC (2003) Determination of tea components with antioxidant activity. J Agric Food Chem 51:4427-4435

Chen J, Lindmark-Månsson H, Gorton L, Åkesson B (2003) Antioxidant capacity of bovine milk as assayed by spectrophotometric and amperometric methods. Int Dairy J 13:927-935

Dave RI, Shah NP (1997) Effectiveness of ascorbic acid as an oxygen scavenger in improving viability of probiotic bacteria in yoghurts made with commercial starter cultures. Int Dairy J 7:435-443

El-Dieb SM, Abd Rabo FHR, Badran SM, Abd El-Fattah AM, Elshaghabee FMF (2012) The growth behavior and enhancement of probiotic viability in bioyoghurt. Int Dairy J 22:44-47

FAO/WHO (2006) Probiotics in food. Health and nutritional properties and guidelines for evaluation. In: FAO Food and Nutrition Paper 85, Rome ftp://ftp.fao.org/docrep/fao/009/a0512e/a0512e00.pdf. Accessed 28 Sept 2013

Gaudreau H, Champagne CP, Remondetto GE, Bazinet L, Subirade M (2013) Effect of catechins on the growth of oxygen-sensitive probiotic bacteria. Food Res Int 53:751-757 
Ghoddusi HB, Hassan K (2011) Selective enumeration of Bifidobacteria: a comparative study. Milchwissenschaft 66:149-151

Hara Y (1997) Influence of tea catechins on the digestive tract. J Cell Biochem S27:52-58

Hervert-Hernández D, Pintado C, Rotger R, Goñi I (2009) Stimulatory role of grape pomace polyphenols on Lactobacillus acidophilus growth. Int J Food Microbiol 136:119-122

ISO 7889/ IDF 117 (2003) Yogurt-enumeration of characteristic microorganisms - colony-count technique at 37 degrees $\mathrm{C}$

Jain NK, Siddiqi M, Weisburger J (eds) (2006) Protective effects of tea on human health. CABI Publishing, Wallingford, Oxfordshire

Jaziri I, Ben Slama M, Mhadhbi H, Urdaci MC, Hamdi M (2009) Effect of green and black teas (Camellia sinensis L.) on the characteristic microflora of yogurt during fermentation and refrigerated storage. Food Chem 112:614-620

Kullisaar T, Zilmer M, Mikelsaar M, Vihalemm T, Annuk H, Kairane C, Kilk A (2002) Two antioxidative lactobacilli strains as promising probiotics. Int J Food Microbiol 72:215-224

Lee HC, Jenner AM, Low CS, Lee YK (2006) Effect of tea phenolics and their aromatic fecal bacterial metabolites on intestinal microbiota. Res Microbiol 157:876-884

Lengkey HAW, Adriani L (2009) Effects of milk fermented with Lactobacillus acidophilus and Bifidobacterium spp., on lactic acid and acetic acid content and on Staphylococcus aureus and Pseudomonas aeruginosa. Biotech Anim Husbandry 25:719-724

Lourens-Hattingh A, Viljoen BC (2001) Yogurt as probiotic carrier food. Int Dairy J 11:1-17

Najgebauer-Lejko D, Sady M, Grega T, Walczycka M (2011) The impact of tea supplementation on microflora, $\mathrm{pH}$ and antioxidant capacity of yoghurt. Int Dairy J 21:568-574

O'Connell JE, Fox PF (2001) Significance and applications of phenolic compounds in the production and quality of milk and dairy products: a review. Int Dairy J 11:103-120

Oliveira RPS, Perego P, Oliveira MN, Converti A (2012) Growth, organic acids profile and sugar metabolism of Bifidobacterium lactis in co-culture with Streptococcus thermophilus: the inulin effect. Food Res Int 48:21-27

Prakash CVS, Indra P (2011) The aroma, taste, color and bioactive constituents of tea. J Med Plants Res 5: 2110-2124

Queipo-Ortuño MI, Boto-Ordóñez M, Murri M, Gomez-Zumaquero JM, Clemente-Postigo M, Estruch R, Cardona Diaz F, Andrés-Lacueva C, Tinahones FJ (2012) Influence of red wine polyphenols and ethanol on the gut microbiota ecology and biochemical biomarkers. Am J Clin Nutr 95:1323-1334

Rodríguez H, Curiel JA, Landete JM, de las Rivas B, de Felipe FL, Gómez-Cordovés C, Mancheño JM, Muñoz R (2009) Food phenolics and lactic acid bacteria. Int J Food Microbiol 132:79-90

Rusak G, Komes D, Likić S, Horžić D, Kovač M (2008) Phenolic content and antioxidative capacity of green and white tea extracts depending on extraction conditions and the solvent used. Food Chem 110:852-858

Sanders ME, Guarner F, Guerrant R, Holt PR, Quigley EM, Sartor RB, Sherman PM, Mayer EA (2013) An update on the use and investigation of probiotics in health and disease. Gut 62:787-796

Saxelin M (2008) Probiotic formulations and applications, the current probiotics market, and changes in the marketplace: a European perspective. Clin Infect Dis 46(suppl 2):S76-S79

Saxelin M, Korpela R, Mäyrä-Mäkinen A (2003) Functional dairy products. Woodhead Publishing Ltd., Cambridge

Shihata A, Shah NP (2002) Influence of addition of proteolytic strains of Lactobacillus delbrueckii subsp. bulgaricus to commercial ABT starter cultures on texture of yoghurt, exopolysaccharide production and survival of bacteria. Int Dairy J 12:765-772

Socha R, Bączkowicz M, Fortuna T, Kura A, Łabanowska M, Kurdziel M (2013) Determination of free radicals and flavan-3-ols content in fermented and unfermented teas and properties of their infusions. Eur Food Res Technol 237:167-177

Tabasco R, Sánchez-Patán F, Monagas M, Bartolomé B, Moreno-Arribas MV, Peláez C, Requena T (2011) Effect of grape polyphenols on lactic acid bacteria and bifidobacteria growth: resistance and metabolism. Food Microbiol 28:1345-1352

von Staszewski M, Pilosof AMR, Jagus RJ (2011) Antioxidant and antimicrobial performance of different Argentinean green tea varieties as affected by whey proteins. Food Chem 125:186-192

Zhu YX, Huang H, Tu YY (2006) A review of recent studies in China on the possible beneficial health effects of tea. Int J Food Sci Technol 41:333-340 